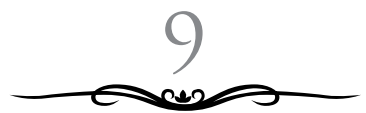

\title{
IMPLEMENTASI LIBRARY 3.0 DI PERPUSTAKAAN \\ IAIN SALATIGA: MASALAH DAN SOLUSINYA
}

\author{
Itmamudin \\ IAIN Salatiga, Jawa Tengah, Indonesia \\ itmam_wafa@yahoo.com
}

\begin{abstract}
The development of technology information influence a library in costumers services. The use of World Wide Web is getting more sophisticated than ever. From web 1.0 with static display of information, it turns to become a web 2.0 in which users can create comments while consuming the information. Now, with the development of web 3.0, the features of web services have been added with more executed in part of users. This article will further describe the implementation of web 3.0 at library of State Institute For Islamic Studies (IAIN) Salatiga. The author remains that the use of web 3.0 does not necessarily mean replacing the use of theancestors, but it just a combination instead.
\end{abstract}

Keywords: Information, Technology, Library.

\begin{abstract}
Abstrak
Perkembangan teknologi informasi mempengaruhi perpustakaan dalam layanan pengguna. Penggunaan website semakin canggih dari sebelumnya. Dari web 1.0 dengan tampilan informasi yang monoton, menjadi web 2.0 di mana pengguna dapat membuat akun sendiri dan menikmanti informasi. Sekarang, dengan perkembangan web 3.0, fitur
\end{abstract}


layanan web telah ditambahkan dengan lebih menarik lagi bagi pengguna. Artikel ini akan lebih menggambarkan pelaksanaan web 3.0 di perpustakaan Institut Agama Islam Negeri (IAIN) Salatiga. Penulis tetap berpandangan bahwa penggunaan web 3.0 tidak berarti menggantikan manusia, tapi itu hanya kombinasi di antara keduanya.

Kata Kunci: Teknologi, Informasi, Library

\section{A. Pendahuluan}

Meminjam istilah Ranganathan (1957), the library is growing organism, ${ }^{1}$ artinya bahwa perpustakaan merupakan organisasi yang harus terus berkembang, Demikian halnya perpustakaan IAIN Salatiga. Menjadi satu-satunya perpustakaan perguruan tinggi milik negara yang berada di Kota Salatiga, tentu Perpustakaan IAIN Salatiga menjadi trendsetterbagi perpustakaan-perpustakaan yang berada di sekitarnya. Hal ini mengharuskan para pustakawan IAIN Salatiga terus meningkatkan kompetensinya dalam berbagai hal agar mampu memberikan warna dalam dunia kepustakawanan di Kota Salatiga maupun di Propinsi Jawa Tengah. Seringkali para pustakawan dilibatkan dalam berbagai kegiatan kepustakawanan, dari mulai Seminar, workshop, Pelatihan, Juri Lomba Perpustakaan dan Pustakawan, Organisasi Pustakawan (IPI), Pendampingan perpustakaan Sekolah, taman baca, perpustakaan masjid, dan lain-lain. Tentu hal ini menjadi kebanggaan sekaligus tantangan bagi para pustakawan IAIN Salatiga untuk terus berkarya untuk kemajuan dunia perpustakaan.

PerpustakaanIAIN Salatiga terus melakukan pengembangan baik kuantitas maupun kualitas, untuk dapat melayani penggunanya dengan baik. Kebutuhan pengguna yang semakin kompleks dan perkembangan teknologi informasi yang begitu pesat turut serta menjadi pendorong perpustakaan untuk terus melakukan pengembangan. Kehadiran berbagai media sosial seperti facebook, tweeter, instagram, line, whatshap dan lain-lain menambah variasi

${ }^{1}$ S.R. Ranganathan, dalam B.K. Sen, "Ranganathan's Five Law's", Annals of Library and Information Studies, Vol. 55, June 2008, hlm. 87-90. 
model pencarian informasi para pengguna. Belum lagi kemudahan akses terhadap internet saat ini sungguh luar biasa, dan hampir dipastikan semua sudut kampus telah terhubung dengan internet. Kemudian sarana yang dimiliki oleh mahasiswa seperti laptop, gadget, tablet dan lain-lain sudah hampir semua mahasiswa memilikinya.

Perkembangan teknologi informasi yang berimbas pada kompeksitas kebutuhan informasi para pengguna tersebut harus ditangkap oleh pengelola perpustakaan dengan melakukan berbagai pengembangan agar perpustakaan mampu menjembatani kebutuhan pengguna. Jika dibiarkan dan perpustakaan tidak melakukan apapun untuk mengadaptasi perkembangan teknologi ini, bukan tidak mungkin, suatu ketika perpustakaan akan ditinggalkan oleh penggunanya.

Berpijak dari pemikiran tersebut di atas, maka penulis merancang sebuah program pengembangan perpustakaan berupa kegiatan Implementasi Library 3.0 di perpustakaan IAIN Salatiga. Adapun tujuan dari kegiatan ini adalah untuk menjawab kompleksitas kebutuhan informasi dan meningkatkan layanan perpustakaan.

\section{B. Pembahasan}

\section{Implementasi Library 3.0 di Perpustakaan IAIN Salatiga}

Sebelum melakukan implementasi program Library 3.0 di perpustakaan, penulis ingin menyampaikan gambaran singkat mengenai fase perkembangan perpustakaan IAIN Salatiga mulai dari fase library 1.0, fase library 2.0 dan fase library 3.0.

a. Fase Library 1.0

Fase Library 1.0 di mulai dari hadirnya web 1.0 di mana website ini hanya dapat di baca tanpa dapat dikreasikan oleh para pengguna. Imas Maesaroh $(2014)^{2}$ mengatakan bahwa generasi

${ }^{2}$ Imas Maesaroh, "Implementasi Library 3.0 di Perpustakaan PTKI", Jurnal Iqra', Vol. 8, No. 2, Tahun 2014. 
library 1.0 di awali dari ditemukannya internet dan Word Wide Web pada tahun 1999 (Miranda, Gualtieri, dan Coccia, 2010) yang kemudian terjadi perubahan yang sangat mendasar yang mengikuti generasi pertama dari Web 1.0 yang memiliki ciri bahwa data dari web site hanya dapat dibaca saja.

Sejak berdiri hingga sekarang, Perpustakaan IAIN Salatiga saat ini telah melewati beberapa fase penerapan pengembangan teknologi informasi di perpustakaan. Dimulai sejak tahun 1997 hingga awal 2003 perpustakaan IAIN Salatiga masih dalam fase perpustakaan manual. Dan mulai tahun 2003 hingga awal 2005 perpustakaan IAIN Salatiga telah berupaya untuk menerapkan sebuah system otomasi perpustakaan bernama SIPISIS yang merupakan pengembangan dari CDSISIS. Meskipun akhirnya, system ini kemudian tidak dapat dipergunakan karena berbagai hal diantaranya minimnya SDM dan sarana dalam implementasinya.

Pada waktu itu, kegiatan yang dilakukan baru sampai pada tahap penerapan system dan input data. Sedangkan OPAC yang ada pada saat itu baru sifatnya memberikan informasi satu arah dari perpustakaan, dan keterlibatan para pengguna sangat minim. Ada beberapa hal mengapa penerapan system tersebut belum terlaksananya di antaranya adalah sumber daya yang sangat minim, sarana yang belum memadai, dan minimnya sumber danadukungan dari pimpinan. Beberapa hal tersebut yang mengakibatkan penerapan system otomasi tidak dapat berjalan sesuai harapan.

b. Fase Library 2.0

Library 2.0. menurut Nugraha (2012: 4) 3 $^{3}$ erupakan model perpustakaan yang layanannya beriorientasi kepada user/patron, kolaborasi antara pustakawan-user, pustakawan-pustakawan dan melibatkan penerapan teknologi web 2.0 pada sistem informasi dan website perpustakaan. Dengan adanya konsep Library 2.0

${ }^{3}$ Nugraha, dalam Vivid Rizqy Manurung, "Perkembangan Tekhnologi Informasi Perpustakaan Menggunakan Digital Library System dan Kaitannya dengan Konsep Library 3.O”, Jurnal Iqra', Vol. 8, No. 2, Tahun 2014. 
ini akan mampu memenuhi berbagai kebutuhan dari generasigenerasi yang mengakses perpustakaan.

Kegagalan perpustakaan IAIN Salatiga menerapkan sistem informasi perpustakaan menggunakan SIPISIS ternyata menjadi pelajaran berharga dalam penerapan system informasi selanjutnya. Hal ini dibuktikan dengan penerapan system informasi yang baru dengan nama system otomasi perpustakaan SIPRUS pada tahun 2005. Pada penerapan system ini, perpustakaan menghabiskan anggaran sekitar Rp. 65.000 .000 sudah termasuk hardware, dan software perpustakaan.

Pasca implementasi Siprus, perpustakaan IAIN Salatiga mengalami lonjakan kemajuan bidang teknologi informasi yang cukup signifikan. Beberapa catatan penulis mengenai perubahan yang signifikan adalah:

1) Sistem pelayanan berbasis computer

2) Kemudahan dalam penelusuran

3) Kemudahan dalam pembuatan laporan

4) Kemudahan dalam pelayanan

5) Kemudahan dalam penghitunan denda

6) Kemudahan dalam mengelola koleksi

7) Kecepatan dan ketepatan dalam melakukan berbagai pekerjaan di perpustakaan.

Dalam fase ini, perpustakaan IAIN Salatiga menjadi salah satu unit yang dianggap cukup mumpuni dalam bidang teknologi dan telah mengadaptasi teknologi dalam melaksanakan kegiatan sehari-hari. Para pengguna dapat memperoleh informasi dari website yang dimiliki oleh perpustakaan dan juga dapat memberikan masukan kepada perpustakaan mengenai berbagai hal pelayanan. Misalnya usulan pembelian buku, usul kegiatan perpustakaan, kritik terhadap perpustakaan dan lain sebagainya.

Disamping itu, perpustakaan juga membuat sebuah OPAC yang memuat berbagai informasi tentang perpustakaan, jadwal kegiatan perpustakaan, penelusuran yang terhubung dengan koleksi digital, penelusuran yang terhubung dengan koleksi fisik, dan berbagai informasi lainnya. Kemudian pada tahun 2013 dan 
2014 IAIN salatiga mendapatkan urutan webometrik yang cukup siginifikan dengan memperoleh nomor urut 1 untuk perpustakaan STAIN di Indonesia dan urutan kelima untuk kategori PTKIN. Namun pada tahun setelahnya perpustakaan IAIN Salatiga mengalami penurunan.

c. Fase Library 3.0

Menurut Imam Maesaroh (2014: 112), ${ }^{4}$ perpustakaan yang menerapkan Library 3.0 adalah OPAC yang sebelumnya berisi data khusus koleksi yang dimiliki perpustakaan, maka dengan penerapan Library 3.0 beberapa adatabase seperti katalog perpustakaan, semua elektronik jurnal yang dilanggan, bahkan sampai database dari Google Scholar dijadikan satu. Disini pengguna ketika melakukan penelusuran, satu kata kunci yang diketik dalam penelusuran akan menampilkan hasil penelusuran yang berasal dari semua data yang terkoneksi dari semua database. Tentu saja ini dikatakan "onengate for all". Selain itu, perpustakaan juga memiliki database repository institusi, dimana para pengguna perpustakaan dapat membuat akun sendiri dan memodifikasi akunnya untuk kemudian dipublikasikan.

Jika mengacu pada pendapat tersebut, maka perpustakaan IAIN sebenarnya sudah memiliki embriountukmenerapkan Library 3.0 di perpustakaan, yaitu adanya OPAC yang sifatnya online dan dapat di akses oleh pengunjung dimanapun dan kapanpun. Hanya saja keterlibatan pengguna belum ada. Sementara ini, OPAC hanya bersifat statis bersifat satu arah, yaitu informasi dari perpustakaan. Disamping itu, web yang ada juga belum dapat di deteksi oleh google scholar dan belum berlangganan elektronik jurnal.

Dengan penerapan Library 3.0 di perpustakaan IAIN Salatiga nantinya, penulis berharap bahwa pengguna semakin mudah mengakses informasi apapun tentang perpustakaan, baik informasi koleksi buku fisik, koleksi jurnal, pengguna memiliki akun, ada komunikasi dua arah dalam segala bentuk kemudahan, dan tak kalah penting setiap informasi yang disampaikan oleh

${ }^{4}$ Ibid., hlm. 112. 
perpustakaan dapat terdeteksi oleh google scholar, sehingga rating webometric perpustakaan IAIN Salatiga dapat terus meningkat.

\section{Program Implementasi Library 3.0}

a. Pembuatan SMS Gateway

Menurut Ardana (2004:35) ${ }^{5}$ SMS Gateway merupakan alat yang fungsinya sebagai penghubung atau jembatan antara aplikasi/ system dengan mobile phone. Pesan-pesan SMS dikirim dari sebuah telepon genggam ke pusat pesan yaitu Short Message Service Centre (SMSC).

Sebagai sebuah sistem aplikasi ini dapat digunakan untuk mengirim dan atau menerima SMS, dan biasanya digunakan pada aplikasi bisnis, baik untuk kepentingan broadcast promosi, servis informasi terhadap pengguna, penyebaran content produk / jasa dan lain lain. Karena merupakan sebuah aplikasi, maka fitur yang ada dalam SMS gateway bisa kita modifikasi sesuai dengan kebutuhan. Beberapa fitur yang umum dikembangkan dalam aplikasi SMS Gateway adalah auto replay, pengiriman masal/broadcat message dan pengiriman terjadwal.

SMS gateway yang akan diterapkan di perpustakaan dan merupakan program tak terpisahkan dari system otomasiperpustakaan antara lain:

1) Auto SMS untuk informasi peringatan jatuh tempo

2) Auto SMS untuk pengguna yang terlambat mengembalikan buku

3) SMS Broadcast untuk informasi dan promosi kegiatan perpustakaan

Penggabungan antara sistem otomasi perpustakaan dan sistem perpustakaan digital dalam system otomasi dan digital yang berbasis Google Scholar

${ }^{5}$ I Made Sri Ardana, "Rancang Bangun Sistem Penerimaan Siswa Baru pada Dinas Pendidikan Kota Denpasar Berbasis Web dan SMS”, Tugas Akhir, Program Studi S1 STIKOM Surabaya, 2004. 
Menurut Risyad (2010: 4), ${ }^{6}$ Google Scholar adalah layanan pencarian materi- materi pelajaran berupa teks dalam berbagai format publikasi seperti doc. dan $p d f$. diluncurkan pada tahun 2004, indeks Google Scholar menyediakan cara yang mudah untuk mencari literatur akademis berupa jurnal-jurnal ilmiah, makalah peer-reviewed, thesis, buku, abstrak dan artikel dari penerbit akademis, komunitas profesional, pusat data pracetak, universitasdengan informasi yang relevan.

Artinya, di sini sumber informasi pada Google Scholar lebih akurat dibanding dengan penggunaan search engine google yang harus menghubungkan terlebih dahulu ke situs-situs dengan sumber informasi yang kurang relevan. Meskipun saat ini Google Scholar masih dalam versi beta, tetapi data basenya yang mencapai jumlah ribuan record sudah lebih dari cukup untuk dapat menemukan berbagai informasi mengenai tulisan ilmiah, laporan penelitian, artikel, dan jurnal-jurnal ilmiah. Sistem yang ada saat ini masih dalam beberapa server yang berbeda satu dengan yang lain dan belum terintegrasi.

Oleh sebab itu, program kami selanjutnya adalah mengembangan sistem otomasi yang sekaligus dapat mengelola koleksi digital dan yang terpenting adalah dapat dikenali oleh Google Scholar.

b. Pembuatan aplikasi OPAC berbasis Android dan dimasukkan dalam Google Play atau Playstore.

Dalam Wikipedia, ${ }^{7}$ Google Play adalahlayanankonten digital milik Google yang melingkupi toko daring untuk produk-produk seperti musik/lagu, buku, aplikasi, permainan, ataupun pemutar media berbasis awan. Layanan ini dapat diakses baik melalui web, aplikasi android (Play Store). Jika sudah tercipta sebuah system

${ }^{6}$ Risyad Fauziansyah Budi, Pengaruh Kualitas Web terhadap Tingkat Kepuasan Penggunaan Google Scholar (Studi Pada Mahasiswa Unair Sebagai Penunjang Kegiatan Akademis ) (Surabaya: Unair, 2010).

${ }^{7}$ Wikipedia., https://id.wikipedia.org/wiki/Google_Play, diakses pada 7 Juni 2016. 
yang terintegrasi maka kemudian langkah selanjutnya adalah membangun OPAC berbasis android dan dimasukkan dalam google play, sehingga semua orang yang menggunakan android dapat dengan mudah mengakses informasi melalui aplikasi ini.

c. Promosi perpustakaan melalui jejaring sosial

Aditya Firmansyah (2010: 10) ${ }^{8}$ mengemukakan bahwa situs jejaring sosial merupakan sebuah situs berbasis pelayanan yang memungkinkan penggunanya untuk membuat profil, melihat list pengguna yang tersedia, serta mengundang atau menerima teman untuk bergabung dalam situs tersebut. Tampilan dasar situs jejaring sosial ini menampilkan halaman profil pengguna, yang di dalamnya terdiri dari identitas diri dan foto pengguna.

Jejaring sosial adalah struktur sosial yang terdiri dari elemenelemen individual atau organisasi. Jejaring ini menunjukan jalan dimana mereka berhubungan karena kesamaan sosialitas, mulai dari mereka yang dikenal sehari-hari sampai dengan keluarga.

Setiap situs jejaring sosial memiliki daya tarik yang berbeda. Namun, pada dasarnya tujuannya sama yaitu untuk berkomunikasi dengan mudah dan lebih menarik karena ditambah fitur-fitur yang memanjakan penggunanya. Dengan beberapa penjelasan di atas dapat diambil kesimpulan bahwa situs jejaring sosial merupakan layanan berbasis web dimana digunakan untuk bersosialisasi dan berkomunikasi dengan pihak lain baik dengan teman, keluarga, maupun suatu komunitas yang memiliki tujuan yang sama.

Sementara ini, perpustakaan melakukan promosi hanya melalui website perpustakaan saja, tanpa menghubungkannya melalui tweeter dan juga facebook. Maka ke depan harapan kami dapat melakukan promosi melalui keduanya.

\section{d. Pengaktifan menu area anggota}

Sebenarnya dalam OPAC yang ada saat ini, pengguna sudah dibuatkan area untuk mengetahui semua kegiatan perpustakaan yang melibatkan pengguna tersebut, namun masih pasif. Hal ini

\footnotetext{
${ }^{8}$ Aditya Firmansyah, Situs Jejaring Sosial Menggunakan Elgg (Bandung:
} Sekolah Teknik Elektro dan Informatika. ITB, 2010), hlm. 54. 
dikarenakan belum dilakukannya promosi untuk pengaktifannya dan pengguna belum tahu manfaat dan cara penggunaanya.

Dengan dibangunnya system yang terintegrasi nanti, maka menu area anggota dapat diaktifkan sesuai dengan tujuan awalnya yaitu ikut melibatkan pengguna dalam berbagai pelayanan yang diberikan kepada para pengguna perpustakaan.

e. Berlangganan jurnal elektronik

Untuk melengkapi sistem yang terintegrasi, maka perpustakaan juga berupaya untuk berlangganan jurnal elektronik. Sementara, ini jurnal yang ada baru jurnal fisik dan itupun tidak berlangganan dan sifatnya hibah dari perguruan tinggi atau lembaga lain.

\section{Masalah dan Solusinya}

a. Sarana dan Prasarana

Sarana dan prasarana dalam implementasi konsep Library 3.0 di Perpustakaan IAIN Salatiga menjadi sangat serius keberadaannya. Perpustakaan IAIN Salatiga saat ini memiliki tiga perpustakaan yang tempatnya berjauhan satu dengan yang lain. Jarak antara kampus satu dengan kampus dua sekitar $2 \mathrm{~km}$ dan dengan kampus 3 sekitar $5 \mathrm{~km}$. Perbedaan tempat yang berjauhan menjadi permasalahan tersendiri dalam melengkapi semua kebutuhan sarana dan prasarana perpustakaan.

Dari pengamatan penulis ada beberapa hal yang terkait dengan masalah sarana dan prasarana yang belum memadai untuk mendukung penerapan Library 3.0 di perpustakaan di antaranya:

1) Jaringan internet

Lokasi perpustakaan yang berada di 3 tempat tentu membutuhkan pemenuhan koneksi jaringan yang mumpuni agar tidak sering terjadi kegagalan koneksi. Sementara ini koneksi yang menghubungkan antara kampus 1, kampus 2 dan kampus 3 sering terjadi disconnected. Jaringan saat ini menggunakan jaringan nirkabel yang cenderung sering terjadi kegagalan koneksi dibandingkan dengan jaringan yang menggunakan kabel. Salatiga sebagai salah satu kota yang memiliki curah hujan yang cukup 
tinggi dan disertai petir, turut serta memberikan dampak pada jaringan karena seringkali peralatan jaringan terkena petir yang mengakibatkan jaringan menjadi rusak.

Untuk mengatasi hal tersebut, ada beberapa hal yang harus dilakukan di antaranya:

a) Membangun jaringan berbasis fiber optic yang menghubungkan kampus 1, kampus 2, dan kampus 3

b) Memasang peralatan anti petir di setiap tower yang digunakan untuk menempatkan peralatan jaringan.

2) Jumlah komputer yang masih sangat minim

Untuk memenuhi kebutuhan pelayanan yang baik, perpustakaan harus memiliki jumlah computer yang tidak sedikit. Dengan jumlah mahasiswa sekitar 5800 an, computer yang ada saat ini dikampus 1 berjumlah 7 komputer, kampus 2 berjumlah 4 komputer dan kampus 3 berjumlah 4 komputer.

Dari 14 komputer yang ada saat ini, 11 di antaranya digunakan oleh para pegawai perpustakaan, baik untuk kegiatan layanan pinjam kembali, absensi, cecking buku, administrasi dan pengolahan. Ini berarti bahwa computer yang digunakan oleh para pengunjung perpustakaan jumlahnya sangat minim yaitu hanya 3 untuk tiga perpustakaan perpustakaan.

Kemudian melihat dari kondisinya, computer yang ada kondisinya sudah sangat memprihatinkan, karena merupakan computer pengadaan sekitar tahun 2010an dan dengan spesifikasi yang masih rendah. Dengan kondisi yang demikian, tentu hal ini dapat menghambat proses implementasi library 3.0 di perpustakaan.

Oleh sebab itu, perlu dilakukan beberapa langkah di antaranya:

a) Melakukan pembelian komputer yang baru dengan spesifikasi yang memadai.

b) Menambah jumlah komputer untuk pengunjung, misalnya untuk penelusuran OPAC, komputer khusus untuk akses digital dan juga akses internet. 
c) Membuat meubelair anjungan untuk menempatkan komputer yang digunakan oleh pengunjung.

b. Koleksi Perpustakaan

Dalam konteks jual beli, koleksi diibaratkan sebagai barang yang akan diperjual belikan. Apakah barang tersebut dapat laku atau tidak, akan mendapatkan harga yang pantas atau tidak, semuanya sangat bergantung dari kualitas barang yang ditawarkan. Maka dalam konteks ilmu perpustakaan koleksi merupakan sesuatu yang ditawarkan kepada para pengunjung perpustakaan. Apakah koleksi tersebut dapat menarik pengunjung atau tidak sangat bergantung kepada kualitas koleksi yang ditawarkan.

Koleksi merupakan kekuatan sebuah perpustakaan, dimana perpustakaan menjadi sangat dibutuhkan oleh pengguna jika mampu menyediakan koleksi yang dibutuhkan oleh pengguna. Terdapat 5 fakultas dan sekitar 22 jurusan yang ada di IAIN Salatiga, namun perpustakaan belum sepenuhnya mampu memenuhi kebutuhan mereka. Apalagi beberapa jurusan baru dibuka, tentu membutuhkan anggaran yang cukup besar untuk bisa memenuhinya.

Dari catatan penulis, perpustakaan IAIN Salatiga saat ini masih konsentrasi pada koleksi fisik saja, kecuali koleksi skripsi dan thesis. Hal ini mengindikasikan bahwa koleksi masih menjadi persoalan yang serius untuk dapat menopang program implementasi library 3.0 di perpustakaan. idealnya perpustakaan harus sudah memulai dengan memiliki koleksi elektronik jurnal, e-book, dan beberapa koleksi elektronik lainya.

Oleh sebab itu, ke depan perlu dialokasikan anggaran yang cukup untuk pengadaan koleksi elektronik agar koleksi yang dimiliki bervariasi tidak hanya pada koleksi fisik saja.

c. Sumber Daya Manusia

Kampus dengan kapasitas mahasiswa sekitar 6000-an saat ini, hanya memiliki tenaga IT sejumlah 4 orang dan itupun tersebar di beberapa fakultas dan unit di IAIN Salatiga. Satu tenaga IT di bagian Teknologi Informasi dan Pangkalan Data (TIPD), satu tenaga IT di bagian keuangan, satu tenaga IT di fakultas Tarbiyah dan 
satu lagi berada di akademik institut. Artinya bahwa perpustakaan belum memiliki tenaga khusus IT yang akan diberikan tugas untuk membackup program implementasi Library 3.0 di perpustakaan.

Melihat jumlah tenaga IT yang ada saat ini, tentu menjadi persoalan yang serius ketika mengimplementasikan Library 3.0 di perpustakaan. Oleh sebab itu, perpustakaan perlu melakukan langkah-langkah berikut ini.

1) Menambah tenaga IT yang khusus menangani teknolologi informasi di perpustakaan.

2) Membekali semua tenaga perpustakaan dengan kompetensi lebih dalam bidang IT.

3) Membuat sebuah pedoman/panduan/jobdiskripsi terkait dengan masalah IT di perpustakaan.

d. Kultur Pengguna Perpustakaan

Perpustakaan sudah memiliki website yang dapat diakses 24 jam oleh pengguna perpustakaan dan juga system otomasi yang sifatnya local dan hanya di akses dari jaringan perpustakaan. Di samping itu, perpustakaan juga telah memiliki system perpustakaan digital yang juga dapat di akses oleh pengguna kapanpun dan dimanapun. Namun pada kenyataannya dalam pengamatan penulis, para pengguna perpustakaan lebih menyukai untuk datang langsung ke perpustakaan dari pada mereka mengunjungi website perpustakaan. Hal ini mengindikasikan bahwa ada dua kemungkinan yang terjadi pada para pengguna.

Kemungkinan yang pertama para pengguna tidak tahu mengenai layanan yang diberikan melalui website perpustakaan yaitu layanan penelusuran melalui web online (OPAC) dan juga melalui layanan koleksi digital. Jika ini terjadi berarti ada mekanisme yang salah dalam memberikan informasi kepada para pengguna mengenai layanan online yang diberikan oleh perpustakaan kepada para pengguna. Jika dikaitkan dengan hal ini, maka keberadaan user education atau pendidikan pemakai perpustakaan sebagai salah satu sarana mengenalkan perpustakaan kepada pengguna belum berjalan sesuai harapan. Selain itu, dapat 
juga dimungkinkan bahwa perpustakaan sangat minim dalam memberikan sosialisasi dan promosi mengenai layanan tersebut.

Kemungkinan kedua adalah bahwa budaya pengguna perpustakaan IAIN Salatiga dalam mencari informasi masih bersifat klasik, sehingga mereka masih senang untuk datang langsung ke perpustakaan dan ketemu dengan koleksi langsung dari pada melalui layanan yang sudah di buat yaitu layanan opac dan juga web digital.

Menyikapi hal ini, ada beberapa langkah yang harus dilakukan untuk mengatasinya, antara lain:

1) Memaksimalkan kegiatan promosi melalui berbagai kegiatan dan kesempatan serta media yang ada untuk mengenalkan perpustakaan dan berbagai layanan yang disediakan untuk pengguna.

2) Memberikan pemahaman kepada para pengguna mengenai kemudahan akses informasi melalui layanan online dari pada mereka harus datang langsung ke perpustakaan.

3) Menambah unit promosi atau tenaga yang khusus untuk melakukan kegiatan promosi yang benar mengenai perpustakaan, sehingga semua layanan yang ada di perpustakaan dapat tersampaikan dengan baik kepada para pengguna perpustakaan.

e. Dana dan Dukungan Manajemen

Keberhasilan program perpustakaan dalam melakukan berbagai layanan terhadap pengguna sangat bergantung dari anggaran dana dan dukungan dari pimpinan lembaga. Semakin besar dana dan dukungan dari pihak manajemen, sangat dimungkinkan tingkat keberhasilannya tinggi, namun sebaliknya jika dana dan dukungan dari pihak manajemen kecil, tentu hal ini juga sangat berbepangaruh pada tingkat keberhasilan program perpustakaan.

Melihat hal ini, penulis merasa bahwa anggaran yang diberikan kepada perpustakaan saat ini masih sangat jauh dari harapan. Hal ini mengacu pada Undang-undang Perpustakaan No. 43 Tahun 2007 yang menyatakan bahwa perguruan tinggi 
harus mengalokasikan dana untuk pengembangan perpustakaan sesuai dengan ketentuan peraturan perundang-undangan guna memenuhi standar nasional pendidikan dan standar nasional perpustakaan. Jika perpustakaan sekolah/madrasah saja wajib mengalokasikan anggaran minimal 5\% untuk perpustakaan, maka seyogyanya perguruan tinggi harusnya lebih dari nilai tersebut.

Dalam catatan penulis, pagu anggaran IAIN Salatiga tahun 2016 sebesar 80 milyar rupiah dengan perincian 40 milyar dari SBSN, dan sisanya dari dana DIPA dan PNBP. Dana 30 milyar untuk gaji, tunjangan, sertifikasi dan lain-lain, dan biaya operasional sebesar 10 miliar rupiah.

Ketika mengacu pada undang-undang tersebut, maka idealnya perpustakaan memperoleh jatah anggaran lebih dari Rp 200.000.000 seperti anggaran perpustakaan tahun ini. Hal ini berarti bahwa keberpihakan lembaga dan dukungan para pimpinan di lembaga kami masih sangat minim, oleh sebab itu, ke depan kami berharap bahwa dana dan dukungan dari pimpinan lebih dari itu.

Dikaitkan dengan implementasi Library 3.0, maka anggaran yang ada saat ini barangkali masih jauh dari harapan. Sementara ini, perpustakaan hanya dapat mengadakan koleksi buku saja, belum dapat mengalokasikan untuk pengadaan koleksi elektronik dan jurnal elektronik. Belum lagi harus membeli berbagai hardware untuk melengkapi keterbatasan computer yanga ada saat ini.

\section{Simpulan}

Penulis yakin bahwa penerapan Library 3.0 di perpustakaan sangat membantu perpustakaan dalam melayani para pengguna. Kemudahan yang dirasakan oleh para pengguna sangat mempengaruhi mereka untuk terus menggunakan perpustakaan ke depan. Penerapan library 3.0 di perpustakaan juga berpengaruh terhadap keberadaan pustakawan sebagai pengelola, sehingga pengelola dituntut untuk terus meningkatkan kompetensi dan inovasi dalam pelayanan terhadap pengguna, sehingga perpustakaan tidak di tinggalkan oleh penggunanya. 


\section{DAFTAR PUSTAKA}

Ardana, I Made Sri. "Rancang Bangun Sistem Penerimaan Siswa Baru pada Dinas Pendidikan Kota Denpasar Berbasis Web dan SMS", TugasAkhir, Program Studi S1 STIKOM Surabaya, 2004.

Budi, Risyad Fauziansyah. Pengaruh Kualitas Web terhadap Tingkat Kepuasan Penggunaan Google Scholar (Studi pada Mahasiswa Unair Sebagai Penunjang Kegiatan Akademis). Surabaya: Unair, 2010.

Firmansyah, Aditya. Situs Jejaring Sosial Menggunakan Elgg. Bandung: Sekolah Teknik Elektro dan Informatika ITB, 2010.

Maesaroh, Imas. "Implementasi Library 3.0 di Perpustakaan PTKI", Jurnal Iqra', Vol. 8, No. 2, Tahun 2014.

Manurung, Vivid Rizqy. "Perkembangan Tekhnologi Informasi Perpustakaan Menggunakan Digital Library System dan Kaitannya dengan Konsep Library 3.O”, Jurnal Iqra', Vol. 8, No. 2, Tahun 2014.

Sen, B.K. "Ranganathan's Five Law's", Annals of Library and Information Studies, Vol. 55, June 2008. 